Titulo de la Tesis

Una Democracia Imperfecta. Redistribución Política de Ingreso en América Latina.

Autor: Ezequiel Molina
Director de tesis: Walter Cont

Tesis presentada para el grado de Magister en Economía de la Universidad Nacional de La Plata, Facultad de Ciencias

Económicas, Departamento de Economía.

Fecha de Presentación: 26 de Junio de 2009.

Tribunal Examinador: Natalia Porto, Walter Cont y Ricardo Bebczuk. 


\title{
An Imperfect Representative Democracy Political Income Redistribution in Latin America*
}

\author{
Ezequiel Molina (UNLP Master Dissertation)
}

June 2009

\begin{abstract}
Although several papers in the political economy literature suggest a positive relationship between income inequality and redistribution, the data for Latin America does not support this claim. Countries with more income inequality also have less redistribution. This paper explores how the degree of imperfection in the political institutions influences equilibrium redistributive tax rates and income distributions. A citizen-candidate model is developed (Osborne and Slivinski, 1996 and Besley and Coate, 1997) in which candidates face a cost for representing other citizens in politics. Political-economic equilibria for different degrees of imperfection of the political system are derived and compared. In particular, two distinct cases are found. Countries where the cost of entry to politics is low can have higher redistribution and lower inequality if the median run as a candidate or , when there is a two candidate equilibria, redistribution and inequality could go either way. On the other hand, countries where the cost of entry is high will not be able to translate the will of the people into political action and will end up with little redistribution and high levels of inequality.
\end{abstract}

JEL Classification: D3, D7, P16.

*I thank my mentor Walter Cont for guidance and support. I also want to thank Santiago Urbiztondo, Leonardo Gasparini, Mariano Tommasi and Gerardo Munck for useful comments and suggestions on earlier drafts. All remaining errors are my own. e-mail: ezequiel.molina@gmail.com 


\section{Introduction}

This paper concerns the redistribution of income through political choice of the tax system in a context of imperfect representative democracy. The paper is motivated by the observation that almost all of the extant theoretical literature on the topic either directs attention to the political institutions of developed countries or presumes that there is no difference between developed and developing countries (e.g., Meltzer and Richard, 1981, Persson and Tabellini, 1994, etc). ${ }^{1}$ As a consequence the classical literature in political economy concludes that higher income inequality should be associated with higher rate of taxation and more redistribution. This argument has been proven incorrect in a recent empirical study for Latin America (Hubner et al, 2006). Hubner et al found that a strong record of democracy and a legislative partisan balance are associated with lower levels of inequality, as are social security and welfare spending under democratic regimes. In fact, the theory is even under dispute for developed countries (Benabou, 1996 , Perotti, 1996 , Moene and Wallerstein, 2001, Iversen and Soskice, 2006). Iversen and Soskice (2006) empirically showed that there is diversity in government redistribution in strong democracies. The authors argue that this is a result of the rules of the political system (majoritarian versus proportional systems).

The rationale of the classical literature is that in a context where there is free access to politics, the median voter's preferred platform would be the one that imposes in an election (Black, 1948 and Downs, 1957). Therefore, when inequality increases the median voter is further away from the mean income and would choose a policy of higher taxes and more redistribution. ${ }^{2}$

Data shows that countries with more income inequality also have less redistribution. I consider that theoretical models used for developed countries do not work because the institutional arena, though similar in writing, is strikingly different in practice. Latin American countries have, to different extents, imperfect representative democracies. While there are other differences among these countries, this paper explores how the degree of imperfection in the political institutions influences equilibrium redistributive tax rates and

\footnotetext{
${ }^{1}$ There is a growing literature on failed states, e.g. Acemoglu and Robinson (2005). However, since Latin American countries are democracies, these models do not usually apply to them.

${ }^{2}$ Using the World Development Indicators (World Bank 2009) I find a negative and non-significant relationship between the Gini coefficient and the Public Sector Expenditure as percentage of the G.D.P. Index restricting the sample to democratic countries .
} 
income distributions.

This paper differs from previous literature on inequality and redistribution on how to model the problem. Building on Osborne and Slivinski (1996) and Besley and Coate (1997), I adapt the citizen-candidate model to address the relationship between inequality and political institutions in Latin America.

To operationalize the model I depart as little as possible from the previous assumptions of the literature on citizen-candidate models. Specifically, the citizen must pay a cost to be a candidate. This is also present in Osborne and Slivinski (1996) and Besley and Coate (1997), but in this case the cost is associated with the workings of the representative democracy. I introduce an imperfection in the political institutions by assuming a fixed entry cost to run as a candidate. In particular, the cost is high in societies where democracy is weakly institutionalized. This means that everyone can vote but not all voices are being heard. Fragments of the population are not being represented in the political arena as it will be shown empirically in section 2 .

This analysis suggests that if access to politics is costly, it could be the case that the median voter's desired platform would not be part of the possible election set. Understanding the cost of access to politics as an index of the quality of the democratic system, it can be deduced that institutional conditions are relevant for the subsequent income institutions dynamics manifested in the economy. Depending on the cost of being a candidate there will be two main cases ${ }^{3}$ :

1) Democracy is strongly institutionalized and the cost of entry is low. When the median voter decides to run there is a one candidate equilibrium and I find similar predictions to Meltzer and Richard 1981. ${ }^{4}$ I also find two and more candidate equilibriums that break the relationship between inequality and redistribution. In these cases equally democratic countries can have different levels of income distribution.

\footnotetext{
${ }^{3}$ I assume that the cost is fixed. I acknowledge that these problems have historical roots that I will not try to disentangle in this paper. This means that initial factor endowments, such as the distribution of wealth, human capital and political power, play a key role in accounting for the dissimilar degree of institutional development. For a detail explanation of this argument see (Engerman and Sokoloff 1997, 2002, 2005; Robinson and Sokoloff 2005)

${ }^{4}$ In Meltzer et al (1981) taxation stops short of full equalization because the median voter recognizes the trade-off between consumption and leisure, i.e. the disincentive effect of a high tax rate. In the present model I do not model production, so this trade-off does not appear.
} 
2) Democracy is weakly institutionalized and the cost of entry is high. The voices of significant fragments of the population are not being heard. In this case redistribution is lower and inequality is higher.

The paper is organized as follows. In Section 2 I develop the links between inequality, redistribution and institutions that will be present in the model. In Section 3 I formalize the argument suggested above. In particular, I propose a model where access to politics is costly and those who hold more political power have more access to economic opportunities. Finally, Section 4 concludes and discusses the agenda for future research.

\section{Inequality, Redistribution and Institutions}

In this section I describe the stylized facts that will be assumed in the model.

\subsection{Income Inequality and Redistribution}

Latin American countries are amongst the most unequal in the world. Table 1 presents evidence of high inequality in Latin American countries compared to other developing and developed nations while Table 2 shows that Latin American countries the fiscal system is of little help in reducing market income inequality and the redistribution effect of the government's fiscal policy is low.

Why is redistribution from rich to poor least present when and where it seems most needed? The so called Robin Hood paradox (Lindert, 2004) is one the fundamental puzzles in the political economy of income redistribution (Iversen, 2006).

In order to address this puzzle, scholars have emphasized both demand and supply side considerations that affect equilibrium redistributive policies which in turn, determine (in part) the extent of income redistribution in a society (Robinson 2008). For example, when

studying the demand side of redistribution in OECD countries, scholars have tended to focus on the preferences of key political and economic actors such as labor unions and employers (Mares 2003), and also of common citizens (e.g. the median voter). The application of the median voters logic to Latin America has its problems. Public opinion surveys, which are the main tool for tapping the determinants of redistributive preferences in large segments of the electorate, shows that there is an intense preference for 
redistribution in the region (Gaviria, 2007 ; Ardanaz, 2009). The reason as to why this preference for redistribution does not translate into political action is not clear. This paper provide a possible reason for this stylized fact. ${ }^{5}$

Table 1: Inequality in Latin America in perspective (Gini coefficient)

Latin America Other Developing Countries OECD Countries

$51.73 \quad 36.18 \quad 28.72$

Source: For Latin America and Other Developing Countries Povcalnet (World Bank 2009) and

SEDLAC. For OECD Countries, Luxembourg Income Study (2009).

Table 2: Redistribution Effect in Latin America in perspective

\begin{tabular}{cccc}
\hline \hline Country & $\begin{array}{c}\text { Market Income } \\
\text { Inequality }\end{array}$ & $\begin{array}{c}\text { Disposable Income } \\
\text { Inequality }\end{array}$ & $\begin{array}{c}\text { Redistribution } \\
\text { Effect }\end{array}$ \\
\hline Latin America & 51.6 & 49.58 & 2.02 \\
Europe & 45.9 & 31.1 & 14.8
\end{tabular}

Note: To measure inequality the Gini coefficient is used. The redistribution effect is the difference between the market inequality (before the government applies the fiscal policy) and the disposable income inequality. The data comes from Goni et al (2009).

\subsection{Institutional Channel}

The key assumption in this paper is that representative democracy does not work in Latin America in the same way that it works on developed countries (i.e. United States, Canada, Great Britain, etc). Note that even though these countries have different political systems (Presidential versus Parliamentary) the workings of their institutions helps translate, with their own idiosyncracies, the will of the people into political action. Many models fall short when equalizing the Presidential system in United States with those in Latin America countries. Let's imagine for the sake of the argument that a person

\footnotetext{
${ }^{5}$ Gaviria (2007) found that income level is a strong predictor of support for redistribution, while suffer from a lack of political representation. Ardanaz (2009) concludes that objective socioeconomic attributes are poor predictors of individual level preferences. In this paper I define utilities in accordance with Gaviria's results.
} 
Figure 1: Supreme Court Justices Tenure in Argentina and the U.S., 1863-1999

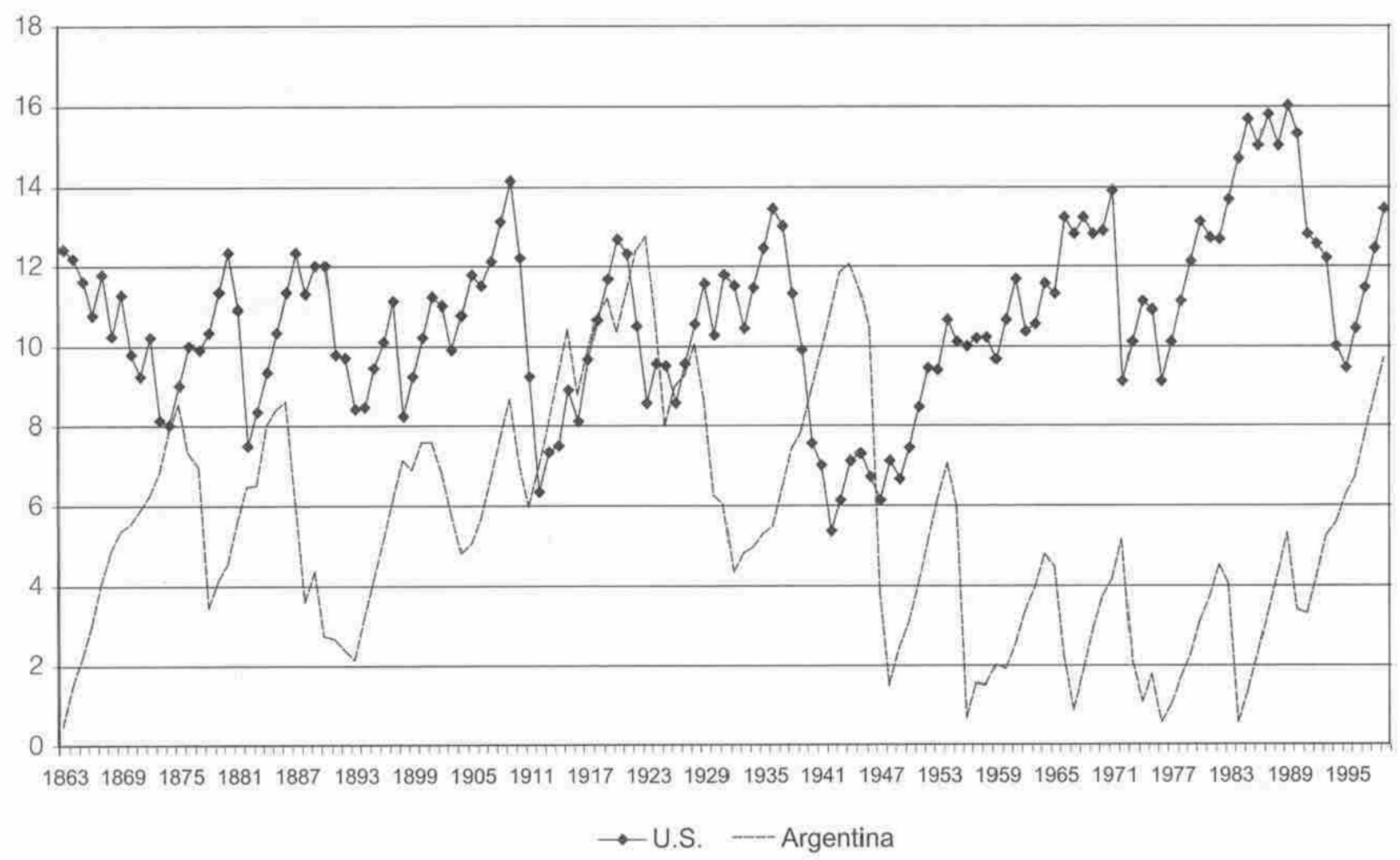

with no previous knowledge of Argentina and USA gets handed both constitutions. After reviewing them, this person would come to the conclusion that the political arena as well as the presidential system are similar in both countries. Then he would then tend to expect similar workings of the political institutions. However, in Argentina's representative democracy the president has far more power than in the United States. The division of power is blurred because formal rules are not supported by informal norms.

Figure 1, reproduced from Iaryczower et al (2002), illustrates this observation using data for the tenure of Supreme Court Justices in Argentina and the United States, 18631999. ${ }^{6}$ Figure 1 shows that while United States Supreme Court Justices tenure ranges from 6 to 16 years for Argentina this number ranges from 0 to 12, with a significantly higher variance and lower mean. This could not be explained by inspecting both constitutions but rather attention should be drawn to their interaction with informal institutions. Thus, we

\footnotetext{
${ }^{6}$ See Iaryczower et al (2002) and Acemoglu and Robinson (2005) for more detail.
} 
will be able to comprehend why several constitutional presidents in Argentina, two in the last 20 years of democracy, appointed a partisan Supreme Court, what came to be known during Menem administration as the "automatic majority". ${ }^{7}$ Furthermore Jones et al (2000) explains why the Argentine Congress plays a limited role in the production of public policy. Provincial governor/party boss(es) are the ones who decide the future of legislators. Therefore this limits legislators ability to develop a professional legislative career and reduces their incentives to specialize and to develop strong legislative institutions. ${ }^{8}$

The importance of adopting a broad-base approach to the understanding of the political institutions is true for all Latin American countries, not just for Argentina. ${ }^{9}$

This imperfection in the representative democratic system can be observed in many indicators. Figure 2 presents the Voice and Accountability Index which is a measure of the extent to which citizens of a country are able to participate in the selection of governments. It includes a number of indicators measuring various aspects of the political process, civil liberties and political rights. ${ }^{10}$ We can observe in the Figure that most Latin American countries have lower values than industrialized ones. Although a more restricted sample, the Global Integrity Index shows the same conclusions. ${ }^{11}$

Table 3 presents the views of the citizen of selected countries about the political systems under which they live.

More than 99 percent of people living in United States or Canada have primarily positive opinions about democracy, expressing support and feelings of pride for their political system. In Latin America the views are substantially different. While Chile has 5

\footnotetext{
${ }^{7}$ Ex-President Nestor Kirchner's term does not appear in the graph, but upon elected to office, his government pursued impeachment of 3 members of the Supreme Court and appointed their replacements.

${ }^{8}$ The idea that legislators need to have incentives to invest to develop a legislative career was reinforce in a recent study. Exploiting a natural experiment in the Argentine House of Representatives and Senate, Dal Bo and Rossi (2008) found that longer terms enhance legislative performance.

${ }^{9}$ See the IADB Project on "Political Institutions, Policymaking Processes and Policy Outcomes" for a summary of how the political arena was shaped over time and how it works in several case studies for individual Latin American countries.

${ }^{10}$ See Kaufmann et al (2008) for the methodology of the indicator aggregation.

${ }^{11}$ The Global Integrity Index is composed by several indicators, among others the Legal Framework Index, The Practical Implementation of this Legal Framework, and the gap between both. For the Practical Implementation Index (2007), Latin American countries in the region (Argentina, Colombia, Costa Rica, Ecuador, Mexico and Peru) average 53 point, 21 point less than the average for the industrialized countries in the sample. (Canada, France, Italy, Spain and United States) See http://www.globalintegrity.org for the methodology used to construct these indicators.
} 
Figure 2: A Measure of the Representation of the Citizens by their Governments

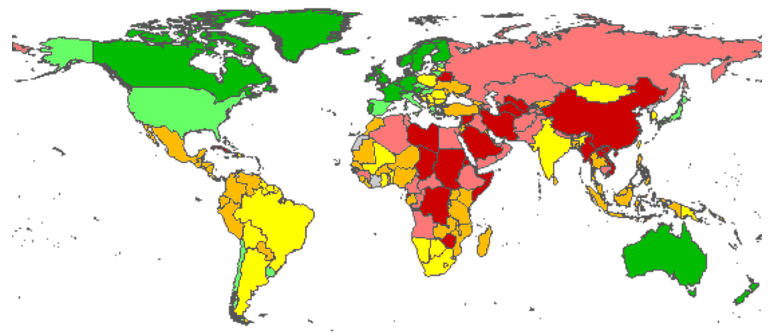

Note: Only Chile and Uruguay are colored in light green, indicating that they are in the 75-90th percentile. The rest is in yellow (50-75th percentile) and orange (25-50th percentile). None is colored in green (90-100th percentile).

percent of the population who express a negative opinion about Democracy, in the rest of the countries there is a double digit figure, reaching 25 and 26 percent in the case of Guatemala and Panama.

In particular, the model's key assumption suggests that poor individuals suffer more from this lack of political representation. Figure 3 presents the percentage of people in each income bracket who have respect and confidence in the political institutions of their own country. The evidence supports the hypothesis that the poor in Ecuador, Nicaragua and Panama have less respect for the political institutions than higher income groups in those countries. ${ }^{12}$ Therefore, the estimates in Figure 3 are consistent with the hypothesis that poor citizens suffers more from a lack of political representation.

In sum, the link between institutions and the cost of entering politics is as follows. Above I have shown that the poor in Latin America suffer from a lack of political representation. This institutional deficiency is introduced in the model as a cost of entry to politics. When this cost is high, the poor can vote but not run as candidates. In this model, the citizen - candidate implements her preferred policy as there is no possible policy commitment. Therefore, this set up implies that when the cost of entry to politics is high, the poor will not be able to participate as candidates and suffer from a lack of political representation.

\footnotetext{
${ }^{12}$ It is interesting to note the case of Chile, the only country that does not display this pattern.
} 
Table 3: Negative Opinions about Democracy and Reaction Towards Political System Developed versus Latin American Countries

\begin{tabular}{ccccc}
\hline \hline Country & Democracy & $\begin{array}{c}\text { Support } \\
\text { Institutions }\end{array}$ & $\begin{array}{c}\text { Proud of } \\
\text { Institutions }\end{array}$ & $\begin{array}{c}\text { Respect for } \\
\text { Institutions }\end{array}$ \\
\hline Canada & 0.74 & High & High & Medium \\
United States & 0.76 & High & High & Medium \\
Chile & 5.19 & Medium & Medium & Medium \\
Ecuador &. & Medium & Low & Medium \\
Guatemala & 25 & Medium & Medium & Medium \\
Nicaragua & 13.9 & Medium & Medium & Medium \\
Panama & 26.2 & Medium & Medium & Medium \\
Paraguay & 13.6 & Medium & Medium & Medium
\end{tabular}

Note: Own estimates based on data from national representative surveys conducted by Vanderbilt University (2006). See annex 2 for more detail.

\section{A Simple Model}

Consider an economy with $n$ agents, $i=\{1, \ldots, n\}$. The agents live infinite periods and are considered "citizen-candidates" (in line with Osborne and Slivinski, 1996; Besley and Coate, 1997). ${ }^{13}$ The timing of the model is the following.

Timing:

1) Any citizen, of any income type, can enter as a political candidate at a cost of $F$.

2) An election is held among those candidates running. Each citizen chooses the candidate by maximizing her expected utility. The candidate who gets a plurality of vote wins, with any ties resolved by the toss of a coin.

3) The elected candidate selects a policy $g_{p}$; if nobody runs, a default policy $\bar{g}$ is implemented.

\footnotetext{
${ }^{13}$ These papers differ in many aspects, but the main difference lies in the way they cope with multiple equilibria. Osborne and Slivinski (1996) assume sincere voting while Besley and Coate (1997) assume strategic voting but impose the requirement that, conditional on any set of candidates, the voting equilibrium must be weakly undominated.
} 
Figure 3: Respect for Political Institutions in Latin America by Income Level (Low vs High Income), 2006

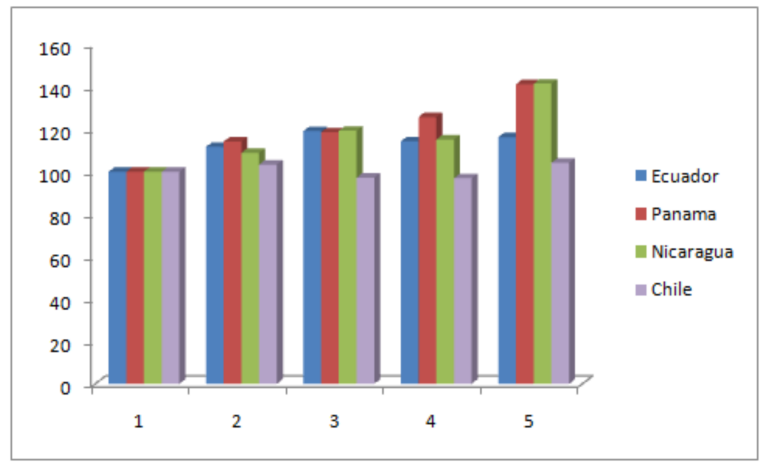

Note: Own estimates based on data from national representative surveys conducted by Vanderbilt University (2006). For more detail see annex 3

As there is no policy commitment, an elected citizen simply sets policy to maximize her utility. The citizen who wins the election implements her preferred policy. Promising anything else is not credible. There are no idiosyncratic utility for holding office (egorent) or from having another making policy (liking a "good-looking" representative) in this model. I assume sincere voting as experimental data have shown that this is the more reasonable assumption. ${ }^{14}$

It is assumed that there is no investment, being the aggregate income equal in all periods. In this model I do not deal with the disincentive effect of a high tax rate. As there is no production, redistribution is costless.

Government levies taxes and allocates resources, being the fiscal policy the tool to affect income distribution. It is also assumed that there must be a balanced budget, so there is no room for intergenerational redistribution.

Individuals cannot credibly threaten to destroy their endowments (Aumman and Kurz, 1977) what would give them more bargain power to negotiate the equilibrium tax rate. To access politics (i.e., to be a candidate), a cost $F$ must be paid. It is assumed that $F$ is a fixed cost, which intuitively reflects how possible is to access politics.(a higher value of $F$ reflects that only people with high income can access to politics, i.e. a more imperfect

\footnotetext{
${ }^{14}$ See Felsenthal and Brichta (1984).
} 
democracy). ${ }^{15}$

Let's also assume, as occurs in every income distribution measure in practice, that median income is less than mean income $\left(y^{M}<\bar{y}\right)$. In each moment of time, the income of individual $i$ is given by:

$$
y_{t+1}^{i}=y_{t}^{i}+(\tau / \bar{y})\left[\left(\bar{y}-y_{t}^{i}\right)\left(g_{t}^{h}-\bar{g}\right)\right]
$$

where $y_{t}^{i}$ is the income of individual $i$ in period $t, \tau$ is the equilibrium tax rate, $g_{t}^{h}$ is the expenditure implemented by the winner in elections in period $t, \bar{y}$ and $\bar{g}$ are the income and expenditure desired by the individual with mean income, which can be proven by assumption constant in time. Adding for all individual incomes in the economy in (1)

$$
\sum_{i=1}^{n} y_{t+1}^{i}=\sum_{i=1}^{n}\left\{y_{t}^{i}+(\tau / \bar{y})\left[\left(\bar{y}-y_{t}^{i}\right)\left(g_{t}^{h}-\bar{g}\right)\right]\right\}
$$

and I obtain 16

$$
y_{t+1}=y_{t}
$$

i.e., the economy's aggregated income is equal for every period, so mean income will not change (and in accordance with (1), the individual with $y_{t}=\bar{y}$, maintains the same income level in each period, so $\bar{g}$, that is the ideal expenditure level for such individual, also remains constant).

Preferences. In each moment of time, preference of individual $i$ are given by:

$$
w^{i}\left(c_{i}, g\right)=(1-\tau) y_{i}+H^{i}(g)
$$

where $c_{i}$ is the consumption from individual $i$ in a given moment and $H^{i}(g)$ is the direct utility the public expenditure brings to individual $i$ (it is assumed that this function is concave and $H(g) \rightarrow 0$ when $g \rightarrow \infty)$.

\footnotetext{
${ }^{15}$ This is a simplification of Engerman and Sokolof theory. Here I assume that the first stage, when the forces generate unequal political power, has already operated and I focus only on the persistence and reproduction of these initial conditions. Endogeneize $F$ is an agenda for future research.

${ }^{16}$ Proofs can be found in the appendix .
} 
Government Budget Constrain It is assumed that taxes are proportional to income, while expenditure benefits all individuals in the same manner. The government budget constraint is

$$
\tau y_{t}=g_{t}
$$

As a consequence, the fiscal policy is progressive and poorer individuals would prefer a higher level of expenditure.

Using the government budget constrain it can be proved that if expenditure have impact only in one period (i.e. if it would not affect the income of the following period as defined in (1)), the level of desired expenditure by the individual $i$ would be

$$
g_{i}^{\star}=H_{g}^{-1}\left(\frac{y^{i}}{y}\right)
$$

This means that poorer individual would prefer a higher level of expenditure (by concavity of $H(g)$ ). Therefore, given the scheme proposed in (1), the conclusion that poor individuals prefer a higher level of expenditure is reinforced.

Participation Constraints For the "citizen candidate" $i$ to decide to enter into politics two conditions must be meet:

$$
\begin{gathered}
y(1-\tau) \geq F \\
E w(I) \geq E w(N I)
\end{gathered}
$$

$I$ denotes that the individual is running for office and $N I$ that she is not running. For the individual $i$ we have

$$
\begin{gathered}
E w^{i}(I)=\sum_{j \in I} p_{j} w^{i}(g)-F \\
E w^{i}(N I)=\sum_{j \in I} p_{j} w^{i}(g)
\end{gathered}
$$

being $p_{j}$ the probability of winning the election for individual $j$ when $i$ is one of them.

Equations (6) and (7) indicates both that: a) the individual must have an income level that allows her to pay the fixed cost to be able to enter, and b) the expected benefit of running for office must be higher than staying out. In this model when no one runs the status quo $\bar{g}$ is implemented. 


\subsection{Cost of Entry to Politics and Multiple Equilibria}

Here I analyze different initial conditions, where the difference is the cost of entry to politics. Only relevant cases will be analyzed, i.e. cases where at least one citizen can access and be a candidate for the election.

\section{Case 1: $F$ is low}

In this case we assume that $F$ is low enough that every individual in the economy satisfy the incentive-compatibility constrain to participate (6), and everyone solve a symmetrical problem. In this case everyone can enter as a candidate to the election, as there is a perfect functioning of the democratic system. The model present more than one equilibrium.

Proposition 1 (One candidate equilibria) The sufficient condition for a one-candidate equilibrium is $w^{M}\left(g^{M}\right)-F \geq w^{M}(\bar{g})$, where the $M$ refers to the median voter, then there is only one candidate running uncontested and her ideal position is the median.

The intuition for this result is as follows. As the policy preferred by the median voter is a Condorcet winner, the median candidate would beat any other individual with different income in an election. If the median has decided to run, no other income type would ever find it worthwhile to incur the entry cost involved in inducing a two-candidate election. If there is a single candidate $E$ whose position is different from the median a citizen whose ideal point is the median could enter and win the election, obtaining a payoff of $w^{M}\left(g^{M}\right)-F \geq w^{M}\left(g^{E}\right)$. Hence, for such a situation to be an equilibrium we need that the cost of entry to the race to be less than what the median candidate wins as a result of implementing his preferred policy compared to the one $E$ would have implemented. In this model it is not profitable for a citizen of the same income type of the candidate running to enter the race as there is no idiosyncratic utility for holding office.

Let's consider that the median is running in the election. Then, the policy selected will be the one preferred by the median voter, that is the one with income

$$
y_{t}^{M}<\bar{y}
$$

and the level of expenditure in $t$ will be

$$
g_{t}^{M}>\bar{g}
$$


Suppose now that there are two candidates in the race with ideal positions symmetrically around the median $(m-\zeta, m+\zeta)$, each receiving half of the votes. If $\zeta$ is small enough then no citizen with ideal position in the interval $(m-\zeta, m+\zeta)$ can enter and win the race and if $\zeta$ is large then there is a citizen that can enter and win. Let $\bar{F}$ be the critical value in $F$ below which all citizen that enter lose and above which some entrants wins.

\section{Proposition 2 (Multiple Two candidate equilibria)}

a Two-candidate equilibria exist if and only if for at least a pair $L=m-\zeta, R=m+\zeta$ this condition holds: For income type $L$ then $(1 / 2)\left[w^{L}\left(g^{L}\right)-w^{L}\left(g^{R}\right)\right] \geq F$. For income type $R$ then $(1 / 2)\left[w^{R}\left(g^{R}\right)-w^{R}\left(g^{L}\right)\right] \geq F$

$b w^{M}\left(g^{L}=w^{M}\left(g^{R}\right)\right.$.Idealpositionsare $(m-\zeta, m+\zeta)$ for some $\zeta>0$ and $\zeta \in\left(0, \zeta_{c}\right)$.

The proposition shows, in particular for the case with strong democratic institutions ( $F$ is low), that in two-candidate equilibriums candidates are going to be close from the median since the cost to participate in the election is low. In this case the median does not find it profitable to enter the race $w^{M}\left(g^{M}\right)-F \leq 1 / 2\left[w^{M}\left(g^{L}\right)+w^{M}\left(g^{R}\right)\right]$ The result shows that equally strong democracies with the same initial conditions can have different redistribution policies and income distribution trends as the contemporary literature in redistributive politics for advanced democracies have shown.

It is also possible to find three or more candidate equilibrium that share the main characteristics as the two-candidate equilibria described above. In this paper I will not study the specifical characteristics of these cases as for I am interested in analyzing the income distribution and the main insight that comes out from this three or more candidate equilibria is the same as the one for two. Equally strong democracies with the same initial conditions can have different redistribution policies and therefore different levels of income distribution.

Case 2: $F$ is high, $F \geq y^{M}(1-\tau)$

In the condition above $\tau$ ) is indicative and necessary to satisfy condition (6)but actually $\tau$ ) is endogenous in this model and chosen by the candidate that win the race. In 
this case the median cannot enter, because (6) it is not satisfied. Three possible subcases can be found:

a) $\bar{y}(1-\tau)>F>y^{M}(1-\tau)$ : candidates $i \in I$ can enter if $y^{M}(1-\tau)<y^{i}(1-\tau)$. This subcase is similar to the one presented in case 1 under one-candidate equilibrium. This means that an individual close to the median can run and win the election. A two or more candidate equilibrium is not possible because no citizen to the left of the median can be a candidate as (6) it is not satisfied.

b) $F=\bar{y}(1-\tau)$. The individual with mean income or a citizen just to the right the mean can enter the race and win the election. Under this scenario income distribution does not change. Again, a two or more candidate equilibria is not possible.

c) $F>\bar{y}(1-\tau)$, only individuals with income above the mean could enter.

Proposition 3 Multiple One candidate equilibria when $F>\bar{y}(1-\tau)$ )

When $F>\bar{y}(1-\tau)$ there are multiple one candidate equilibria. This equilibrium is not unique as there are a range of citizen - candidates that can win the race, depending on the level of $F$.

a If $F=Y_{c 1}\left(1-\tau_{c 1}\right)$ and $w^{Y_{c 1}}\left(g^{Y_{c 1}}\right)-F \geq w^{Y_{c 1}}(\bar{g})$ then there is a range of possible citizen candidates that can run and win the election. The winning candidate $\in\left[Y_{c 1}, Y_{c 2}\right]$ income range, where $Y_{c 1}=F /\left(1-\tau_{c 1}\right) . Y_{c 2}>Y_{c 1}$ and $Y_{c 2}=$ $Y_{c 1}+\left[w^{H F}\left(g^{H F}\right)-w^{H F}\left(g^{M A G}\right)\right]$ where $H F$ is the citizen candidate with income equal to $Y_{c 1}$ and $M A G$ a citizen candidate with income equal to $Y_{c 2}$.

$b$ If $Y_{c 2}=Y_{H I}$, where $H I$ is the citizen with highest income. The winning candidate $\in\left[Y_{c 1}, Y_{c 2}\right]$ income range.

c If $F=Y_{c 1}=Y_{H I}$. Then the highest income citizen is the only candidate running and win the race. There is no fiscal policy and income market inequality is equal to disposable income inequality.

Given that I am interested in analyzing equilibrium situations, I assume that at least one individual in that income range satisfied (7). Therefore, an individual with the income above $F$

$$
y^{i} \geq Y_{c 1}\left(1-\tau_{c 1}\right)=F
$$

where $y^{i} \in\left[Y_{c 1}, Y_{c 2}\right]$ 
will win the election and the expenditure level in $t$ will be

$$
g_{t}^{h}=g_{t}^{i}<\bar{g}
$$

Again, a two or more candidate equilibria is not possible.

\subsection{Analyzing Results}

From the cases in section 3, we observed that when the cost of entering politics is low (i.e., case 1 of section 3) the preferred policy by the median voter is imposed in a one-candidate equilibrium and multiple equilibria arise in a two candidate equilibrium that will support different levels of income distribution for countries with the same initial conditions. On the other hand, when the cost of entry is high (specifically, above mean income in case $2 c$ of section 3), the policy implemented implies less expenditure to the one preferred by the mean voter (and thus is also less from the one desired by the median). Finally, when the cost of running for office is near mean income, the model predicts stagnation of the income distribution.

Below I focus in the income distribution for the individuals of the economy in the different scenarios I raised before.

1) $g_{t}^{h}=\bar{g}$.

This is a trivial case where the individual with mean income win the election or nobody runs.

$$
y_{t+1}^{i}=y_{t}^{i} \quad \forall i
$$

In this case, there is no redistributive policy, thus, no change for the income distribution.

2) $g_{t}^{h}=g_{t}^{M}>\bar{g}$.

This case could arise when the cost of entry to politics is low in a one-candidate equilibrium. Those individuals with income below the mean will have

$$
y_{t+1}^{i}>y_{t}^{i}
$$

while those with income above the mean will have

$$
y_{t+1}^{i}<y_{t}^{i}
$$

The income of the median citizen increases and the desired expenditure decreases . Every individual with less income than the mean voter will have their income level raised by 
a range that will approach to zero as her income approaches to the mean income in the economy, and the reverse will happen to those individuals with income above the median. Therefore, I conclude that when there is a strong institutionalized democracy, the income distribution will tend to reflect the positions of the median voter under one-candidate equilibrium. (i.e., in this case the income distribution will tend to be egalitarian).

3) $g_{t}^{h}<\bar{g}$.

This case present itself when there are strong restrictions on the access to politics. ( $F$ high). Therefore, those individuals with less income than the mean one will have

$$
y_{t+1}^{i}<y_{t}^{i}
$$

while those with more income than the mean one will have

$$
y_{t+1}^{i}>y_{t}^{i}
$$

Individuals with income below the mean citizen will have hers income level reduced, while those with incomes above the mean will have their income level raised each period. In this case, when there is weak democracy, the income distribution will be oscillating above a threshold of high inequality. Table 4 presents the average inequality in the history for Latin America, as well as the lower and upper bound for the region. This information support the theoretical finding that in weaker democracies inequality tend to be higher. The number of breaks in the trend for Latin America in the last decades shows that the relationship is not monotonic and that countries in Latin America oscillate in a threshold of high income inequity, with the lower bound of income inequality in the history of the region being higher than inequality in any country in the advanced democracies. In the annex the information is disaggregated by country.

Table 4: History of Levels of Inequality and Trend Breaks in Latin America

\begin{tabular}{ccccc}
\hline \hline Country & $\begin{array}{c}\text { Average } \\
\text { Inequality }\end{array}$ & $\begin{array}{c}\text { Lower } \\
\text { Bound }\end{array}$ & $\begin{array}{c}\text { Upper } \\
\text { Bound }\end{array}$ & $\begin{array}{c}\text { Number of } \\
\text { Breaks in the Trend }\end{array}$ \\
\hline Latin America & 54.59 & 51.25 & 57.98 & 3
\end{tabular}

Note: To measure inequality the Gini coefficient is used. Own calculations based on SEDLAC(2009). 


\section{Conclusions}

This study has analyzed the redistribution of income through political choice of the tax system in a context of imperfect representative democracy. Earlier studies have implicitly assumed that the hard letter of the constitution was enough to understand how the political system works. In contrast, I provide evidence that this is not the case for Latin America, where fragments of the population are not represented in the political arena. In this way I try to disentangle how the degree of imperfection in the political institutions influence equilibrium redistributive tax rates and income distributions. I develop a citizen-candidate model and find 2 distinct cases:

1) Democracy is strongly institutionalized and the cost of entry is low. When the median voter decide to run we have a one candidate equilibrium and I find similar predictions to Meltzer and Richard 1981. I also find two and more candidate equilibriums that break the relationship between inequality and redistribution. In these cases equally democratic countries with the same initial conditions can have different levels of income distribution.

2) Democracy is weakly institutionalized. The voices of substantial fragments of the population are not being heard. In this case income distribution will be highly unequal.

This analysis relies on a number of simplifying assumptions. Specifically, the citizens are fully informed, there is no production, citizens vote sincerely and there is no idiosyncratic utility for holding office (ego-rent). ${ }^{17}$ This framework could be extended to account for these cases.

In this model there are no political parties. Agenda for future research could include the possibility of party formation to cope the cost of entry to politics. This amendment of the model would increase the critical level of $F$ at which the median voter logic is broken and generates less redistribution and higher inequality.

Future research should also model the cost of entry endogenously and could take a dynamic approach. In a dynamic setting other profitable strategies would arise for the citizen

\footnotetext{
${ }^{17}$ For redistributive models where there is imperfect information on part of the citizen on the underlying structure of the economic system see Piketty (1995). For models where candidates have imperfect information about the distribution of citizen ideal positions see Calvert (1985), Roemer (1994) and Wittman (1997).
} 
candidates. In particular, they would have incentives to tilt the competitive scenario in their favor in future elections. This would make equilibria more complex but I expect the main results to be robust to this specification, i.e. that redistribution is lower and inequality higher in countries where institutions are weaker (the cost of entry is higher). Dynamic models could help understand why inequality is a persistent problem in Latin America.

Nevertheless, these results are quite promising for further research that places an emphasis in understanding the workings of informal institutions and how they interact with formal institution to make distinct political systems. This will allow us to improve our understanding of political redistribution in Latin American countries. 


\section{$5 \quad$ References}

- Acemoglu, D. and Robinson, J.A. 2005 . Economic Origins of Dictatorship and Democracy. Cambridge University Press, Cambridge.

- Aumann, R.J. and Kurz, M, 1977. Power and taxes in a multi-commodity economy. Israel Journal of Mathematics, 27: 185-34.

- Austen-Smith, D., 2000. Redistributing income under proportional representation. Journal of Political Economy, 108:1235-69.

- Benabou, R. 1996. Inequality and Growth. In National Bureau of Economic Research MacroAnnual, ed. Bernanke, B. and Rotemberg,J. Cambridge: MIT Press 11:1174.

- Besley, T. and Coate, S. 1997. An economic model of representative democracy. Quarterly Journal of Economics,112:85-14.

- Black, D. 1948. On the rationale of group decision-making. Journal of Political Economy,56:23-34.

- Downs, A. 1957. An economic theory of democracy. New York, Harper and Row.

- Calvert, R. 1985. Robustness of the multidimensional voting model: candidate motivations, uncertainty and convergence. American Journal of Political Science. 29:69-95.

- Engerman, S.L., and Sokoloff, K. L. 1997, Factor endowments, institutions, and differential paths of growth among new world economies: A view from economic historians of the United States, In: Haber, S., Economic Growth and Latin American Economic Historiography. (MIT Press, Cambridge, MA).

- Engerman, S. L. and Sokoloff, K. L. 2002, Factor endowments, inequality, and paths of development among new world economies, NBER Working Paper 9259.

- Engerman, S. L. and Sokoloff, K. L. 2005 Colonialism, inequality, and long-run paths of development NBER Working Paper w11057.

- Felsenthal, D. and Brichta, A. 1985. Sincere and strategic voters: An Israeli study, Journal of Political Behavior, 7:4-20.

- Gaviria, A. 2007 Social mobility and preferences for redistribution in Latin America, Economia Colombia.

- Goni, E., J.H. Lpez, and L. Servn 2009 Fiscal reform for social equity in Latin America, mimeo, World Bank, Washington DC.

- Huber, E., Nielsen, F., Pribble, J. and Stephens, J. 2006. Politics and Inequality in Latin America and the Caribbean.American Sociological Review ,71:943-63. 
- Huber, E., Mustillo, T. and Stephens, J. 2008. Politics and Social Spending in Latin America. The Journal of Politics,70:420-36.

- Iaryczower, M., Spiller, P. and Tommasi, M. 2002. Judicial Independence in Unstable Environments: Argentina 1938-1998 , American Journal of Political Science 46:699-716. - Iversen, T. and Sosike, D. 2006. Electoral Institutions and the Politics of Coalitions: Why Some Democracies Redistribute More Than Others. American Political Science Review,100:165-181.

- Iversen, T. 2006 Democracy and Capitalism. Oxford Handbook of Political Economy. Oxford University Press, Oxford.

- Jones, M., Saiegh, S., Spiller, P. and Tommasi, M. 2002. Professional politicians amateur legislators: The Argentine Congress in the XXth century, American Journal of Political Science: 20:656-69.

- Kaufmann, D., A. Kraay and M. Mastruzzi 2008. Governance Matters VI: Governance Indicators for 1996-2007.

- Lindert, P. 2004. Growing public: Social spending and economic growth since the eighteenth century. Cambridge University Press, Cambridge.

- Mares, I. 2003 The Politics of Social Risk: Business and Welfare State Development. Cambridge University Press, New York.

- Meltzer, A.H., and Richard, S.F. 1981 A rational theory of the size of government. Journal of Political Economy, 89:914-27.

- Moene, K.O. and Wallerstein, M. 2001. Inequality, Social Insurance and Redistribution. American Political Science Review 95: 85974.

- Robinson, D. and Sokoloff, K. L. 2005. Historical roots of Latin American inequality. In Inequality in Latin America and the Caribbean: Breaking with History. World Bank, chapter 5.

- Osborne, M.J. and Slivinsky, A. 1996 A model of political competition with citizencandidates. Quarterly Journal of Economics 11:65-96.

- Perotti, Roberto. 1996. Growth, Income Distribution and Democracy:What the Data Say. Journal of Economic Growth 1:14987.

- Persson, T., Roland, G., and Tabellini, G. 2000. Comparative politics and public finance. Journal of Political Economy, 108:1121-61.

- Persson, T., and Tabellini, G. 2000. Political Economics: Explaining Economic Policy. MIT Press, Cambridge, Massachusetts. 
- Piketty, T. 1995. Social mobility and redistributive politics. Quarterly Journal of Economics, 110:551-84.

- Robinson, J. 2008. The political economy of redistributive policies. Mimeo, Harvard.

- Roemer, J. 1994. A theory of policy differentiation in single issue electoral politics. Social Choice and Welfare, 11:355-80.

- Roemer, J. 1999. The democratic political economy of progressive income taxation. Econometrica, 67:1-19.

- Wittman, D. 1977. Candidates with policy preference: a dynamic model. Journal of Economic Theory, 14:180-89. 


\section{Appendix}

Proposition 0: Given the law of motion of income (1), with $y_{t}$ exogenous and without investment, then $y_{t+1}=y_{t} \forall t$.

Proof: Adding in (1) for all individuals:

$$
\sum_{i=1}^{n} y_{t+1}^{i}=\sum_{i=1}^{n}\left\{y_{t}^{i}+(\tau / \bar{y})\left[\left(\bar{y}-y_{t}^{i}\right)\left(g_{t}^{h}-\bar{g}\right)\right]\right\}
$$

Solving the sums:

$$
y_{t+1}=y_{t}+(\tau / \bar{y})\left[n \bar{y}\left(g_{t}^{h}-\bar{g}\right)-y_{t}\left(g_{t}^{h}-\bar{g}\right)\right]
$$

Then, applying the definition of mean the last two terms of the right expression cancel out, and

$$
y_{t+1}=y_{t}
$$

Proof of Proposition 1: If the median citizen enters the race no other citizen would be willing to enter. Let's prove this proposition by contradiction. Assume that the citizen candidate $s$ enters the race. We know by definition that conditions (6) and (7) must be met. For the citizen candidate $s$ to enter the race he must have at least $1 / 2$ probability of winning it. If this were not the case, the candidate that loses will prefer to withdraw and not incur in the cost of entry. For $s$ to have at least half the probability of winning it, $s$ would have to be the median. But as there are no ego rent in this model, no other median would enter the race and pay the fixed cost once other median citizen have already done it, because $w^{M}\left(g^{M}\right)-F \geq w^{M}\left(g^{M}\right)$ when $F>0$.

The second part involves proving that the median has incentives to enter the race. If the median does not enter the race, the status quo $\bar{g}$ will prevail. If the median decides to enter the race, she will win and have as a payoff $w^{M}\left(g^{M}\right)-F$. Since we know that $w^{M}\left(g^{M}\right)-F \geq w^{M}(\bar{g})$ the median will enter the race and win it. From the condition above $F \leq w^{M}\left(g^{M}\right)-w^{M}(\bar{g})$ and $F<y^{M}\left(1-\tau^{M}\right)$ where $\tau^{M}$ is the tax rate selected by the median after she wins the election. 
Proof of Proposition 2: We will show the proof for citizen of income type $L$ but the proof is symmetric for the citizen income type $R$. Let's denote $G$ as the utility of staying out of the race for citizen of income type $L$

$$
G=w^{L}\left(g^{R}\right)
$$

and $D$ as the utility of winning the race for citizen of income type $L$

$$
D=w^{L}\left(g^{L}\right)
$$

Also denote the differential utility of winning the race for income type $L$ is

$$
P=\left[w^{L}\left(g^{L}\right)-w^{L}\left(g^{R}\right)\right]
$$

In any two candidate equilibrium each candidate will have $1 / 2$ probability of winning. If this were not the case, the candidate that loses will prefer to withdraw and not incur in the cost of entry $F$. For the probability to be $1 / 2$ for each the candidates's position must be symmetric around the median. For this to be an equilibrium, and letting $\zeta$ be the distance from the median this requirement implies that for candidate of income type L

$$
1 / 2 D+1 / 2 G-F \geq G
$$

or

$$
(1 / 2)\left[w^{L}\left(g^{L}\right)-w^{L}\left(g^{R}\right)\right] \geq F
$$

There are multiple two candidates equilibria functions of $\zeta$. Let's define a particular $\zeta$ to characterize the two candidate equilibria for this particular $\zeta$. If $\zeta=1 / 6$, and knowing that $m=1 / 2$. In this case no other citizen would wish to enter the race, because it will not have the necessary votes to win the election. Those to the left of $L$ would vote for $L$ and those to the right of $R$ would vote for $R$. As for the citizens in the interval between the $L$ and the median and between $R$ and the median, half would choose the median and the other half $L$ and $R$ respectively.

For the two candidates, $L$ and $R$ to enter the race, it is needed that

$$
(1 / 2)\left[w^{L}\left(g^{L}\right)-w^{L}\left(g^{R}\right)\right] \geq F
$$

and a symmetric condition for $R$ 


$$
(1 / 2)\left[w^{R}\left(g^{R}\right)-w^{R}\left(g^{L}\right)\right] \geq F
$$

For this to be possible $F \leq \bar{F}$, where $\bar{F}$ is a function of $\zeta$. The value of $\bar{F}$ is the maximum of two conditions, whichever is binding.

(i) $F=(1 / 2) P$

(ii) $y^{(M-\zeta)}\left(1-\tau^{L} / 2-\tau^{R} / 2\right)=F$

$\zeta$ could take values in the interval $\left(0, \zeta_{c}\right)$. If $\zeta=0$ two candidate equilibria is not possible because the two candidates would be in the position of the median and as there are no ego rent in the model, one of them would rather not run and save the cost of entry. The value of $\zeta_{c}$ will be determined by the above conditions. If the restrictions on $\bar{F}$ are not binding $\zeta_{c}$ is equal to $1 / 3$, its maximum possible value to guarantee a two candidate equilibria. If $\zeta>1 / 3$ citizens $\in\left(y^{L}, y^{R}\right)$ between the two candidates would have incentives to run because they would win the election. If $\bar{F}$ is binding $\zeta_{c}$ will be lower than $1 / 3$ but always above $0 . \zeta_{c}$ takes a value in the interval $(0,1 / 3)$.

\section{Proof of Proposition 3:}

If a citizen - candidate with an income $\in\left[Y_{c 1}, Y_{c 2}\right]$ enters the race, no other citizen would be willing to enter. First, no citizen to the right of $Y_{c 2}$ will enter because it will collect less votes that her rival. Second, no citizen to the left of $Y_{c 1}$ will enter because condition (6) is binding, $F=Y_{c 1}(1-\tau)$.

Now, consider that $Y_{c 1}$ enters the race. Then, no one else wishes to enter the race. The second part involves proving that she incentives to enter the race. If $Y_{c 1}$ does not enter the race, the status quo $\bar{g}$ will prevail. If $Y_{c 1}$ decides to enter the race, she will win and have as a payoff $w^{Y_{c 1}}\left(g^{Y_{c 1}}\right)-F$. Since we know that $w^{Y_{c 1}}\left(g^{Y_{c 1}}\right)-F \geq w^{M}(\bar{g})$ so $Y_{c 1}$ will enter the race and win it.

Now, consider that $y>Y_{c 1}$ enters the race. Then, no candidate to the right wishes to enter the race. For this to be an equilibrium it is needed that no one $\in\left[Y_{c 1}, y\right)$ has an incentive to enter. The condition $w^{y}\left(g^{y}\right)-F \geq w^{y}\left(g^{Y_{c 1}}\right)$ implies that the value of $F$ is such that candidates $\in\left[Y_{c 1}, y\right)$ prefers to let $y$ win the race and not have to pay the fixed cost to enter the race. The second part involves proving that she incentives to enter the race. As we showed above $Y_{c 1}$ have incentives to enter the race. A candidate to the right 
of $Y_{c 1}$ will have more incentives to enter, since status quo is father away from her preferred policy.

Now, consider $F=Y_{c 1}=Y_{H I}$. Then the highest income citizen is the only candidate running and win the race. There is no fiscal policy and income market inequality is equal to disposable income inequality. 


\section{Annex for Table 2}

Table 5: Annex - Redistribution in Latin America in perspective

\begin{tabular}{|c|c|c|c|}
\hline Country & $\begin{array}{l}\text { Market Income } \\
\text { Inequality }\end{array}$ & $\begin{array}{l}\text { Disposable Income } \\
\text { Inequality }\end{array}$ & $\begin{array}{c}\text { Redistribution } \\
\text { Effect }\end{array}$ \\
\hline Argentina & 49.99 & 48.11 & 1.88 \\
\hline Brazil & 56.03 & 54.27 & 1.76 \\
\hline Chile & 47.23 & 45.57 & 1.66 \\
\hline Colombia & 56.76 & 52.16 & 4.6 \\
\hline Mexico & 50.98 & 49.44 & 1.54 \\
\hline Peru & 48.59 & 47.94 & 0.65 \\
\hline Latin America & 51.6 & 49.58 & 2.02 \\
\hline Austria & 38 & 25 & 13 \\
\hline Belgium & 47 & 29 & 18 \\
\hline Denmark & 49 & 29 & 20 \\
\hline Finland & 49 & 32 & 17 \\
\hline France & 42 & 31 & 11 \\
\hline Germany & 43 & 28 & 15 \\
\hline Greece & 47 & 36 & 11 \\
\hline Ireland & 53 & 34 & 19 \\
\hline Italy & 48 & 37 & 11 \\
\hline Luxembourg & 41 & 24 & 17 \\
\hline Netherlands & 39 & 26 & 13 \\
\hline Portugal & 49 & 38 & 11 \\
\hline Spain & 47 & 35 & 22 \\
\hline Sweden & 45 & 29 & 16 \\
\hline UK & 52 & 34 & 18 \\
\hline Europe & 45.9 & 31.1 & 14.8 \\
\hline
\end{tabular}

Note: To measure inequality the Gini coefficient is used. The data comes from Goni et al (2009).

\section{Annex for Table 3}

Table 3 is based on data from national representative surveys conducted by Vanderbilt University during 2006 for individual countries in Latin America as well as in United States and in Canada. The table reports the answers to the following questions: a) What does democracy primarily means to you? Percentage of negative opinions. The following questions ask citizens to evaluate different statements in an scale from 1 to 7 
; b) Support for (your own country) Political System c) Respect for (your own country) Political Institutions d) Proud of living under (your own country) Political System. For answer where the mean of the population was between 1-3 I label them Low, for 3.01-5 Medium and for 5.01-7 High.

\section{Annex for Figure 3}

The figure 3 is based on data from national representative surveys conducted by Vanderbilt University during 2006 for Chile, Ecuador, Nicaragua and Panama. The table reports the answers to the following questions: Evaluate in an scale from 1 to 7 your Respect for (your own country) Political Institutions. Using another question on people identification to different income brackets I construct a variable for the mean answer in each income group. In order to make the differences more visible the first income group (lower income population) is used as a base group and is assigned a value of 100 . 


\section{Annex for Table 4}

Table 6: Annex - History of Levels of Inequality and Trend Breaks in Latin America

\begin{tabular}{ccccc}
\hline \hline Country & $\begin{array}{c}\text { Average } \\
\text { Inequality }\end{array}$ & $\begin{array}{c}\text { Lower } \\
\text { Bound }\end{array}$ & $\begin{array}{c}\text { Upper } \\
\text { Bound }\end{array}$ & $\begin{array}{c}\text { Number of } \\
\text { Breaks in the Trend }\end{array}$ \\
\hline Argentina & 51.2 & 48.7 & 54.1 & 3 \\
Bolivia & 58 & 56.1 & 60.1 & 3 \\
Brazil & 58.3 & 54.8 & 62.8 & 4 \\
Chile & 54.7 & 51.8 & 56.1 & 4 \\
Colombia & 55.7 & 50 & 58.3 & 1 \\
Costa Rica & 47.3 & 44 & 49.8 & 2 \\
Ecuador & 55 & 49.5 & 62.8 & 2 \\
El Salvador & 51.2 & 48.4 & 53.4 & 5 \\
Guatemala & 55.1 & 53.2 & 58.2 & - \\
Honduras & 55.2 & 51.1 & 59.3 & 2 \\
Mexico & 52.3 & 49.9 & 54.6 & 2 \\
Nicaragua & 53.3 & 50.2 & 56.3 & 1 \\
Panama & 55.5 & 53.8 & 56.7 & 4 \\
Paraguay & 56 & 53.2 & 58.4 & 4 \\
Peru & 52.1 & 48.6 & 55.5 & 5 \\
Uruguay & 44.4 & 42.1 & 47.1 & 2 \\
Venezuela & 45.4 & 41.3 & 47.6 & 6
\end{tabular}

Note: To measure inequality the Gini coefficient is used. Own calculations based on SEDLAC(2009). 